20

\title{
Исследование эффективности оптического просветления кожи растворами глицерина методом конфокальной микроспектроскопии комбинационного рассеяния света
}

\author{
(C) И.Ю. Янина ${ }^{1,2,3}$, И. Шлойзенер ${ }^{3}$, Ю. Ладеманн ${ }^{3}$, В.В. Тучин ${ }^{1,2,4}$, М.Е. Дарвин ${ }^{3}$ \\ ${ }^{1}$ Саратовский национальный исследовательский государственный университет им. Н.Г. Чернышевского, \\ 410012 Саратов, Россия \\ ${ }^{2}$ Национальный исследовательский Томский государственный университет, \\ 634050 Томск, Россия \\ ${ }^{3}$ Charité - Universitätsmedizin Berlin, corporate member of Freie Universität Berlin, Humboldt-Universität zu Berlin, \\ Berlin Institute of Health, Department of Dermatology, Venerology and Allergology, \\ Center of Experimental and Applied Cutaneous Physiology, \\ 10117 Berlin, Germany \\ ${ }^{4}$ Институт проблем точной механики и управления РАН, \\ 410028 Саратов, Россия \\ e-mail: irina-yanina@yandex.ru
}

Поступила в редакцию 07.01.2020 г.

В окончательной редакции 05.02.2020 г.

Принята к публикации 28.02.2020 г.

\begin{abstract}
Изучено влияния растворов глицерина различной концентрации и времени экспозиции на эффективность оптического просветления (ОП) в интактной свиной коже при анализе спектров комбинационного рассеяния (КР), записанных на разных глубинах. Обнаружено, что раствор 80\% глицерина и 20\% диметилсульфоксида (ДМСО) в течение 45 min проникал через роговой слой. Увеличение ОП было достигнуто при использовании смесей оптических просветляющих агентов (ОПА) с ДМСО и дистиллированной водой. Так, наибольшая эффективность ОП наблюдалась при использовании смеси 60\% глицерина и 40\% воды в течение $45 \mathrm{~min}$ (увеличение в 3.4 раза на глубине $80 \mu \mathrm{m}$ ). Таким образом, показана возможность контроля оптических параметров кожи на глубине порядка $80 \mu \mathrm{m}$ с помощью метода конфокальной микроскопии комбинационного рассеяния.
\end{abstract}

Ключевые слова: ДМСО, роговой слой кожи, спектры комбинационного рассеяния, глубина проникновения, усилители проникновения.

DOI: $10.21883 /$ OS.2020.06.49407.52-20

\section{Введение}

В настоящее время большое количество оптических методов активно применяются in vivo для неинвазивной диагностики кожи, а также мониторинга проникновения в кожу и действия лекарственных препаратов и косметических средств [1,2]. К данным методам относятся конфокальная микроспектроскопия комбинационного рассеяния (КМКР) света [3-7], мультифотонная томография $[8,9]$, инфракрасная спектроскопия [10-12], оптическая когерентная томография (ОКТ) [13-15], отражательная спектроскопия [16,17], флуоресцентная спектроскопия $[18,19]$, терагерцовая спектроскопия $[20,21]$ и другие методы [22]. Все вышеперечисленные оптические методы исследования кожи имеют принципиальное ограничение, не позволяющее получать информацию хорошего качества из глубоких слоев кожи. Данное ограничение связано с тем, что все слои кожи: эпидермис, дерма и гиподерма характеризуются сильным светорассеянием и поглощением [23]. Как правило, на практике глубина зондирования не превышает $200 \mu \mathrm{m}$. Исключение составляет метод ОКТ, где при меньшем пространственном разрешении глубина сканирования составляет несколько миллиметров [24].

Для увеличения глубины зондирования, пространственного разрешения оптических систем и улучшения контраста получаемых изображений был предложен метод оптического просветления (ОП), позволяющий контролировать оптические свойства кожи, в первую очередь за счет существенного уменьшения рассеяния. Эффект ОП основан на согласовании показателей преломления структурных компонент биотканей и окружающего их вещества [23]. Основы теории и актуальные достижения по ОП кожи для применения in vitro и in vivo были описаны в ряде недавних публикаций [25-27]. Многие препараты признаны эффективными для местного ОП in vivo, такие как глицерин, диметилсульфоксид (ДМСО), йогексол, пропиленгликоль, полиэтиленгликоль, растворы глюкозы и фруктозы [23-31]. Таким образом, ОП стало простым и общедоступным методом, используемым для увеличения глубины зондирования различных оптических систем за счет управления оптическими свойствами кожи. ОП может быть также эффективно при разработке мето- 
дов функциональной визуализации и лазерной терапии, поскольку часто объект исследования расположен на оптически недосягаемой глубине в биологической ткани (например, при удалении или идентификации чернил татуировок in vivo [32]). В данном случае глубина проникновения света имеет решающее значение для обеспечения лучшего качества изображения и достижения точности спектроскопической информации, полученной из более глубоких слоев кожи. ОП активно применяется в клинических исследованиях для улучшения визуализации различных биологических тканей (кожа, сухожилия, мозг и другие) [33]. Изучение эффектов, оказываемых ОПА на оптические свойства биологических тканей и крови, является важной задачей для визуализации in vivo. Например, для лазерной терапии уменьшение рассеяния исследуемой ткани позволяет снизить дозу лазерного излучения, необходимую для проведения терапии. На данный момент было опубликовано большое количество статей, обзоров и монографий по данной тематике, подробный обзор которых представлен в работе [25].

Тем не менее, несмотря на большое количество публикаций, проблема поиска наиболее эффективного ОПА, времени экспозиции на коже, а также физических и химических усилителей его проникновения является актуальной. Недостаточно внимания уделено изучению влияния ОПА на параметры и компоненты кожи in vivo, их обратимость и время восстановления, т.е. на безопасность местного применения ОПА на коже. Было показано, что продолжительное применение высококонцентрированных ОПА может оказывать негативный эффект на кожу, например, локальный гемостаз, сжатие, дегидратацию, иногда некроз. Некоторые ОПА служат усилителями проникновения и могут вызывать изменение в морфологии кожи из-за диссоциации коллагеновых волокон $[13,34,35]$ и физиологического эффекта дегидратации, оказываемого на сосудистую сеть дермы [36]. Таким образом, чтобы избежать или уменьшить негативный эффект на коже, критически важно найти оптимальные ОПА, их концентрации, допустимые времена и количество экспозиций на коже in vivo. Часто для увеличения эффективности ОП полностью или частично удаляется роговой слой, что является слабоинвазивным воздействием. Таким образом, является важным и актуальным исследовать эффективность ОП интактной кожи, т. е. не оказывая влияния на целостность ее структуры.

Для ОП большой интерес представляет дерма. В недавних исследованиях ex vivo при помощи метода КМКР показано, что ОПА различных типов и концентраций могут приводить к дегидратации коллагена дермы [37], что связано с уменьшением (вытеснением посредством действия ОПА) слабо и сильно связанной воды [38], что хорошо описывает эффект ОП уменьшение градиента показателей преломления изза оттока воды в дерме, приводящий к уменьшению рассеяния кожи. Данные измерения проводились ex vivo на свиной коже с частично удаленным роговым слоем.
В связи с этим интерес представляют результаты данных измерений ex vivo без предварительного воздействия на роговой слой - на интактной коже, что должно показать реальную картину воздействия ОПА на барьер рогового слоя, на дегидратацию нижележащих слоев кожи, включая дерму, и на эффективность метода ОП. Целью данного исследования являлось определение эффективности ОП растворами глицерина различной концентрации и времени экспозиции на интактную свиную кожу в эксперименте ex vivo без предварительного воздействия на роговой слой.

\section{Материалы и методы}

\section{Подготовка образцов}

В качестве модели кожи человека ex vivo была выбрана кожа уха свиньи (возраст свиней $\approx 0.5$ year). Свиные уши получали со свиной фермы не позднее, чем через $4 \mathrm{~h}$ после забоя. Процедура подготовки кожи к измерениям включала в себя очистку от грязи при помощи холодной проточной воды, удаление остатков воды бумажным полотенцем, удаление щетины ножницами, не нарушающими структуру рогового слоя кожи. Подготовленные к измерениям свиные уши хранились в холодильнике при температуре $+5^{\circ} \mathrm{C}$. Максимальное время хранения составляло 5 дней. Перед началом измерений кожа находилась в течение $30 \mathrm{~min}$ в лаборатории с контролируемыми значениями температуры и влажности для адаптации к внешним условиям. Десять различных свиных ушей использовались в эксперименте. Каждое исследование проводилось на трех образцах кожи, не имеющих визуальных повреждений. Образцы кожи вырезались скальпелем и отделялись от хряща для каждого отдельного эксперимента (размер образцов $\approx 1 \times 1 \mathrm{~cm}$, толщина $\approx 1 \mathrm{~mm})$. Далее образцы кожи помещались на предметное стекло, и на поверхности кожи размещался бумажный диск диаметром $12 \mathrm{~mm}$, на который со стороны контакта с кожей наносился тот или иной ОПА в количестве $100 \mu 1$ (табл. 1). Время экспозиции составляло 5, 15,30 и $45 \mathrm{~min}$. После удаления диска излишки агента удалялись фильтровальной бумагой. Контрольные измерения проводились на коже без нанесения ОПА.

\section{Метод КМКР}

Ex vivo измерения на коже свиного уха проводились на конфокальном микроскопе КР River D International B.V. (model $3510 \mathrm{SCA}$, Роттердам, Голландия). Спектральное разрешение прибора составляло $2 \mathrm{~cm}^{-1}$. Для получения спектров КР в диапазоне волновых чисел 400-2200 cm-1 использовалось излучение с длиной волны $785 \mathrm{~nm}$ (полупроводниковый лазер Innovative Photonic Solutions, Монмут Джанкшен, Нью-Джерси, США). Мощность излучения на поверхности кожи составляла $20 \mathrm{~mW}$, время экспозиции $5 \mathrm{~s}$. Точка начала 
Таблица 1. Показатели преломления использованных ОПА

\begin{tabular}{l|c}
\hline \multicolumn{1}{c|}{ ОПА } & $\begin{array}{c}\text { Показатель } \\
\text { преломления } \\
\text { на } 785 \mathrm{~nm}\end{array}$ \\
\hline $\begin{array}{l}\text { 100\% Глицерин } \\
\text { (ГаленоФарм, Санкт-Петербург) }[39]\end{array}$ & 1.4666 \\
$90 \%$ Глицерин +10\% ДМСО & 1.4670 \\
$80 \%$ Глицерин +20\% ДМСО & 1.4673 \\
$60 \%$ Глицерин+40\% дистиллированная вода & 1.4119 \\
40\% Глицерин+60\% дистиллированная вода & 1.3844 \\
100\% ДМСО (AcrosOrganics, Китай) & 1.4699
\end{tabular}

измерений выбиралась вблизи поверхности кожи, измерение профиля проводилось до глубины $90 \mu \mathrm{m} \mathrm{c} \mathrm{шагом}$ $5 \mu \mathrm{m}$. Для точного определения положения поверхности кожи первые $20 \mu \mathrm{m}$ измерялись с шагом $2 \mu \mathrm{m}$. Положение поверхности кожи определялось по характеру изменения интенсивности линии КР кератина на $1665 \mathrm{~cm}^{-1}$, как $\left(I_{\max }-I_{\min }\right) / 2$ [40]. Далее все значения глубины отсчитывались относительно этого положения. Для каждого образца кожи измерялись шесть профилей из различных точек образца. Глубина проникновения ОПА в кожу вычислялась при использовании программы SkinTools, поставляемой в комплекте с КМКР. В основе методики определения глубины проникновения ОПА в кожу лежит определение относительного содержания ОПА на различных глубинах рогового слоя кожи при сравнении спектра комбинационного рассеяния (КР) ОПА с модельными спектрами КР компонентов рогового слоя кожи [41]. Предварительная обработка данных заключалась в получении истинного спектра КР путем вычитания сигнала автофлуоресценции кожи из зарегистрированных спектров КР для линий КР на 1003 и $1665 \mathrm{~cm}^{-1}$, используя линейную функцию.

\section{Результаты исследования и обсуждение}

Спектры КР необработанных образцов свиной кожи ex vivo на различных глубинах и используемых ОПА представлены на рис. 1 и 2 соответственно.

Из рисунков видно, что, несмотря на частичное перекрытие линий КР кожи и ОПА (глицерин, ДМСО, вода), можно выделить области, где перекрытие линий КР минимально, например линии КР на 1003 и $1665 \mathrm{~cm}^{-1}$. Таким образом, для определения эффективности ОП целесообразно исследовать изменение интенсивности этих линий КР в коже.

После экспозиции ОПА на кожу спектр КР обработанной кожи представляет собой суперпозицию спектров КР кожи и ОПА, что наиболее заметно в верхних слоях рогового слоя. Глубина проникновения ОПА в кожу различается и представлена в табл. 2. Принимая во внимание среднюю толщину рогового слоя свиной кожи, равную $18 \pm 2 \mu \mathrm{m}$ [42], можно заключить, что

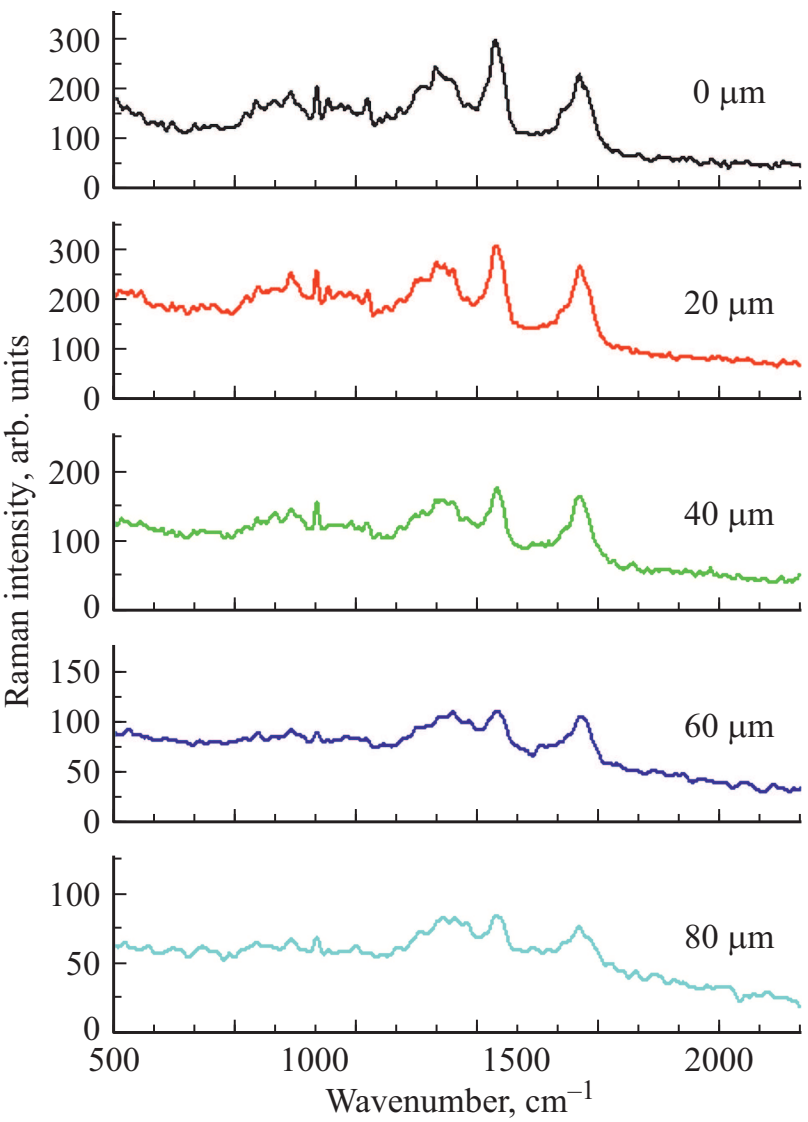

Рис. 1. Спектры КР интактной свиной кожи, измеренные ex vivo на различной глубине. Интенсивность сигнала КР представлена в относительных единицах, что соответствует числу фотонов, записанных детектором КМКР.

ДМСО проникает через роговой слой при определенных временах экспозиции, что согласуется с данными литературы [43]. Из других ОПА только раствор 80\% глицерина $+20 \%$ ДМСО в течение 45 min проникал через роговой слой, что, по всей видимости, связано с проникающей способностью ДМСО. Максимальные глубины проникновения ОПА, близкие к толщине рогового слоя, были достигнуты в случаях применения 100\% глицерина и раствора 90\% глицерина $+10 \%$ ДМСО в течение $45 \mathrm{~min}$, а также раствора $80 \%$ глицерина $+20 \%$ ДМСО в течение 15 и $30 \mathrm{~min}$.

Эффективность ОП удобно определять по увеличению интенсивности линий КР белков как $I_{\text {ОП }} / I$ - отношение интенсивности сигнала КР после нанесения ОПА $\left(I_{\text {OП }}\right)$ к интенсивности сигнала КР без нанесения ОПА (I), вычисленную на определенной глубине кожи [37]. В этой работе эффективность ОП оценивалась как отношение интенсивностей линий КР на $1003 \mathrm{~cm}^{-1}$ (колебания фенилаланина/мочевины) и на $1665 \mathrm{~cm}^{-1}$ (колебания амида $I$ ) образцов кожи, обработанных и не обработанных ОПА (контрольные образцы) на различных глубинах. На серии рис. 3 представлены рассчитанные значения эффективностей ОП для использованных ОПА. Предва- 
Таблица 2. Глубина проникновения ОПА в свиную кожу еx vivo

\begin{tabular}{|c|c|c|c|c|}
\hline \multirow{3}{*}{ ОПА } & \multicolumn{4}{|c|}{ Время экспозиции на коже, min } \\
\hline & 5 & 15 & 30 & 45 \\
\hline & \multicolumn{4}{|c|}{ Глубина проникновения, $\mu \mathrm{m}$} \\
\hline $\begin{array}{l}100 \% \text { глицерин } \\
90 \% \text { глицерин }+10 \% \text { ДМСО } \\
80 \% \text { глицерин }+20 \% \text { ДМСО } \\
60 \% \text { глицерин }+40 \% \text { вода } \\
40 \% \text { глицерин }+60 \% \text { вода } \\
100 \% \text { ДМСО }\end{array}$ & $\begin{array}{c}12.1 \pm 2.4 \\
11.7 \pm 3.4 \\
12.4 \pm 3.2 \\
10.4 \pm 5.9 \\
9.7 \pm 3.6 \\
13.9 \pm 4.0\end{array}$ & $\begin{array}{c}12.7 \pm 4.8 \\
14.6 \pm 2.9 \\
15.8 \pm 4.5 \\
11.5 \pm 3.0 \\
9.5 \pm 6.5 \\
27.1 \pm 7.6\end{array}$ & $\begin{array}{l}12.1 \pm 3.4 \\
14.5 \pm 3.2 \\
15.5 \pm 4.5 \\
11.9 \pm 3.8 \\
10.3 \pm 2.9 \\
30.0 \pm 5.1\end{array}$ & $\begin{array}{l}15.7 \pm 3.6 \\
17.1 \pm 4.1 \\
19.1 \pm 2.2 \\
13.0 \pm 4.2 \\
12.4 \pm 4.4 \\
32.9 \pm 7.8\end{array}$ \\
\hline
\end{tabular}
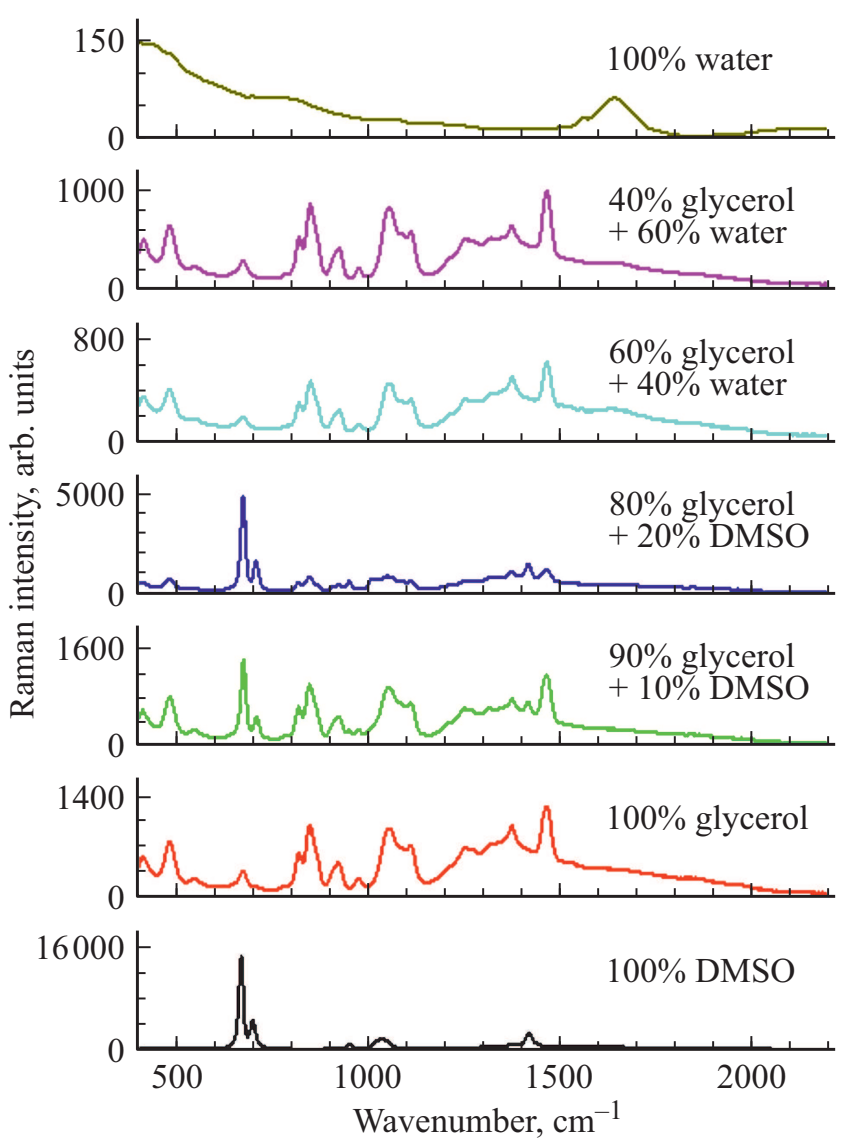

Рис. 2. Спектры КР использованных ОПА. Интенсивность сигнала КР представлена в относительных единицах, что соответствует числу фотонов, записанных детектором КМКР.

рительно отметим, что при использовании 100\% ДМСО достигалась наибольшая эффективность ОП: значения 3.7 на глубине $80 \mu \mathrm{m}$ при экспозиции в течение $30 \mathrm{~min}$. Известно, что ДМСО разрушает липидный барьер рогового слоя [43] и изменяет межфибриллярное расстояние между коллагеновыми волокнами дермы [44]. По этой причине ДМСО чаще всего применяют в качестве химического усилителя проникающей способности ОПА и гораздо реже как самостоятельный ОПА.
Увеличение ОП было достигнуто при использовании смесей ОПА с ДМСО и дистиллированной водой. Так, наибольшее значение эффективности ОП наблюдалось при использовании смеси 60\% глицерина и 40\% воды в течение $45 \mathrm{~min}$ (увеличение в 3.4 раза на глубине $80 \mu \mathrm{m})$. При этом достигается максимальная эффективность порядка 4-6 на глубине $60 \mu \mathrm{m}$ за $45 \mathrm{~min}$ действия ОПА. Такой результат именно для этого ОПА объясняется оптимальным соотношением компонентов раствора для получения его низкой вязкости, равной $10.8 \mathrm{mPa} \cdot \mathrm{s}$, что почти в 14 раз меньше, чем у $100 \%$ глицерина $(1410 \mathrm{mPa} \cdot \mathrm{s})$ [45], и в то же время не очень сильным уменьшением показателя преломления при разбавлении водой, а именно от 1.472 для 100\% глицерина до 1.416 для $60 \%$ глицерина (табл. 1). Отметим, что на длине волны $785 \mathrm{~nm}$ средний показатель преломления рогового слоя 1.54, а рассеивателей (клеточных мембран, липидных включений и пр.) - около 1.68 .

Значение имеет также баланс содержания воды в ОПА и самой коже, концентрацию которой в среднем по роговому слою и эпидермису можно оценить на уровне $40 \%$ [41]. В этом случае вода практически не принимает участия в диффузионных процессах [46], и молекулы глицерина в основном осуществляют диффузию в кожу и там связывают молекулы тканевой воды и тем самым повышают показатель преломления межклеточного пространства, тем самым снижая коэффициент рассеяния верхних слоев кожи. Гигроскопичность глицерина такова, что когда он находится во влажной среде (коже), он связывает воду до тех пор, пока не будет достигнут уровень $\approx 55 \%$. Это означает, что каждая молекула глицерина привлекает около шести молекул воды [47]. Такая концентрация хорошо соответствует оптимальной величине ОП, полученной в нашем исследовании.

Поскольку коэффициент рассеяния $\mu_{s}$ рогового слоя в десять раз больше, чем у эпидермиса и дермы (например, для кожи человека на длине волны $700 \mathrm{~nm}$ $\mu_{s} \cong 500 \mathrm{~cm}^{-1}$ для рогового слоя, $55 \mathrm{~cm}^{-1}$ для эпидермиса и $54 \mathrm{~cm}^{-1}$ для дермы [23]), то, несмотря на небольшую толщину рогового слоя, он играет решающую роль в просветлении кожи и увеличении глу- 

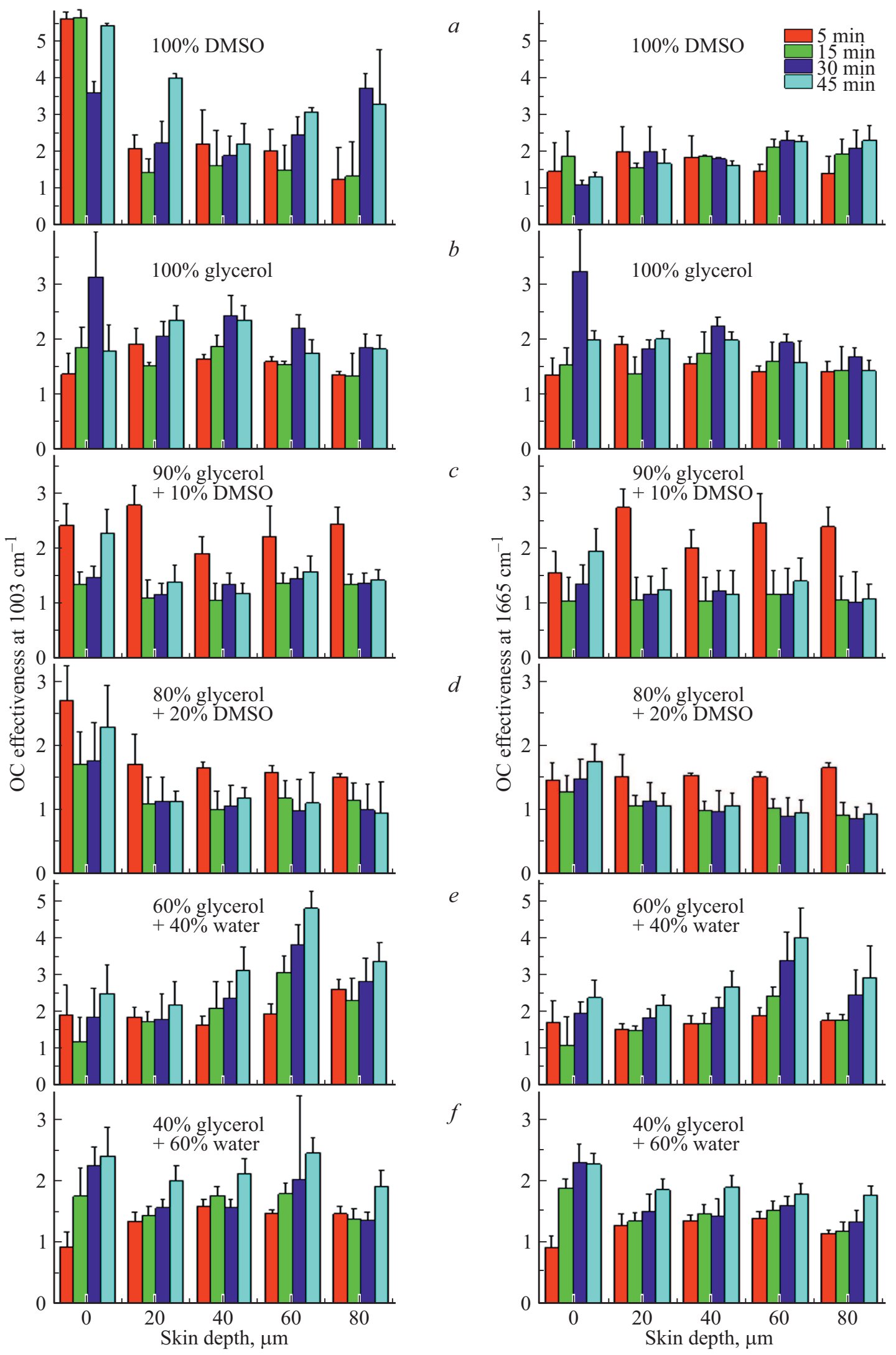

Pис. 3. Эффективность ОП для образцов кожи, обработанных 100\%ДМСО (a); 100\% глицерина (b); раствором 90\% глицерина $+10 \%$ ДМСО $(c)$; раствором $80 \%$ глицерина $+20 \%$ ДМСО $(d)$; раствором $60 \%$ глицерина $+40 \%$ воды $(e)$ и раствором $40 \%$ глицерина $+60 \%$ воды $(f)$ для разных времен экспозиции $(5,15,30$ и $45 \mathrm{~min})$ для линии КР на 1003 (левая колонка) и $1665 \mathrm{~cm}^{-1}$ (правая колонка). 
бины зондирования кожи вплоть до слоя дермы. Этот результат хорошо согласуется с данными работы [48], в которой исследовалось оптическое коллимированное пропускание кожи лабораторных крыс ex vivo при доступе глицерина с обеих сторон кожи - эпидермальной и дермальной, а эффективность рассчитывалась, исходя из уменьшения коэффициента рассеяния кожи. Близкие результаты также получены в работе [28] для свиной кожи при измерениях ex vivo методом ОКТ, где оптимальной была определена концентрация глицерина, равная 70\% за время воздействия около $1 \mathrm{~h}$.

Что касается проникновения молекул глицерина в эпидермис кожи, то в работе [8] с помощью методов спектроскопии когерентного антистоксова рассеяния света (КАРС) и двухфотонной автофлуоресценции были достигнуты примерно такие же глубины чрезкожного проникновения 40\%-дейтерированного глицерина в эпидермис человека in vivo, а именно $10 \mu \mathrm{m}$ за время $1 \mathrm{~h}$. Исследовались два типа растворов глицерина - в воде и ксантановом геле. Было показано, что постоянное количество глицерина в коже in vivo достигалось примерно через час, что отличается от результатов, полученных ex vivo на образце кожи живота человека, когда остаточная диффузия все еще наблюдалась через $4 \mathrm{~h}$ и регистрировалась вплоть до $24 \mathrm{~h}$. Несмотря на некоторые количественные различия между объектами исследования на коже и формулами агентов, важным является вывод о том, что за счет обмена веществ, потоотделения, миграции кожного сала, микрофлоры и т.п. проникновение глицерина через кожу в условиях in vivo может существенно ускоряться.

\section{Выводы}

Как правило, на практике для обеспечения более эффективного ОП кожи удаляется часть рогового слоя, что является слабоинвазивным воздействием. В настоящей работе проведено исследование ex vivo влияния местного нанесения растворов глицерина разной концентрации на увеличение эффективности ОП для интактной кожи без удаления/нарушения рогового слоя. Показано, что применение ОПА на интактной коже также приводит к заметному ОП. Эффективность ОП, по всей видимости, связана с вытеснением воды из глубинных областей рогового слоя и заменой ее на глицерин, что подтверждается измеренными глубинами проникновения ОПА в роговой слой. Изменение концентрации воды в растворе глицерина с 0 до $60 \%$ приводит к уменьшению эффективности ОП (максимальные значения эффективности ОП изменяются от 3.4 до 1.9 при экспозиции $45 \mathrm{~min}$ ) до глубины $80 \mu \mathrm{m}$. При добавлении малых концентраций ДМСО (10 или 20\%) максимальные значения эффективности ОП изменяются от 2.2 до 1.5 при экспозиции $5 \mathrm{~min}$, что наиболее выражено в эпидермисе $(0-40 \mu \mathrm{m})$.
Максимальная эффективность ОП, порядка 4-6 на глубине $60 \mu \mathrm{m}$, достигается в течение $45 \mathrm{~min}$ действия 60\%-раствора глицерина в воде. Это объясняется характерной степенью гигроскопичности глицерина, низкой вязкостью раствора и его значительным показателем преломления, за счет чего при диффузии молекул глицерина в кожу повышается показатель преломления межклеточного пространства и снижается коэффициент рассеяния верхних слоев кожи.

Продемонстрировано, что, несмотря на небольшую толщину рогового слоя, он играет решающую роль в просветлении кожи и увеличении глубины ее оптического зондирования вплоть до слоя дермы, что обусловлено почти десятикратным превышением коэффициента рассеяния рогового слоя по сравнению с эпидермисом и дермой.

Увеличение ОП было достигнуто на глубине $80 \mu \mathrm{m}$ (в 2-4 раза) при использовании 60\%-раствора глицерина в воде для всех времен экспозиции. Эффективность ОП 100\% глицерина, 90\%-раствора глицерина в ДМСО, а также 40\%-раствора глицерина в воде оказались практически сравнимыми.

\section{Финансирование работы}

И.Ю. Янина выражает благодарность ДААД и Министерству образования и науки Российской Федерации за оказанную финансовую поддержку в рамках гранта „Программа Михаила Ломоносова — Linie B, 2019 (57447934)“ (арт. № 91728614) (стажировка в клинике Charité - Universitätsmedizin Berlin). Работа В.В. Тучина была поддержана грантом РФФИ № 18-52-16025 НЦНИЛ_а (определение оптимального ОПА).

\section{Соблюдение этических стандартов}

Разрешение на выполнение измерений ex vivo на свиной коже было получено от комиссии по ветеринарному и пищевому контролю района Даме-Шпревальд, Германия.

\section{Конфликт интересов}

Авторы заявляют, что у них нет конфликта интересов.

\section{Список литературы}

[1] Schulz R., Yamamoto K., Klossek A., Rancan F., Vogt A., Schütte C., Rühl E., Netz R.R. // Biophys J. 2019. V. 117. N 5. P. 998.

[2] Matta M.K., Zusterzeel R., Pilli N.R., Patel V., Volpe D.A., Florian J., Oh L., Bashaw E., Zineh I., Sanabria C., Kemp S., Godfrey A., Adah S., Coelho S., Wang J., Furlong L.A., Ganley C., Michele T., Strauss D.G. // JAMA. 2019. V. 321. N 21. P.2082.

[3] Krafft C., Popp J. // Anal. Bioanal. Chem. 2015. V. 407. N 3. P. 699. 
[4] Choe C.-S., Lademann J., Darvin M.E. // Skin Pharmacol. Physiol. 2015. V. 28. P. 318.

[5] Zhang L., Cambron T., Niu Y., Xu Z., Su N., Zheng H., Wei K., Ray P. // J. Vis Exp. 2019. N 151. P. e60186.

[6] Osseiran S., Dela Cruz J., Jeong S., Wang H., Fthenakis C., Evans C.L. // Biomed. Opt. Express. 2018. V. 9. N 12. P. 6425.

[7] Bielfeldt S., Schoder V., Ely U., van der Pol A., de Sterke J., Wilhelm K.-P. // Opt. Express. 2010. V. 18. N 15. P. 15289.

[8] Sarri B., Chen X., Canonge R., Grégoire S., Formanek F., Galey J.B., Potter A., Bornschlögl T., Rigneault H. // J. Control Release. 2019. V. 308. P. 190.

[9] Ahn J., Kim K.H., Choe K., Lim J.H., Lee S.K., Kim Y.S., Kim P. // Biomed. Opt. Express. 2018. V. 9. N 8. P. 3974.

[10] Kikuchi S., Aosaki T, Bito K, Naito S, Katayama Y. // Skin Res. Technol. 2015. V. 21. P. 76.

[11] Wolf M., Halper M., Pribyl R., Baurecht D., Valenta C. // Int. J. Pharm. 2017. V. 519. N 1-2. P. 198.

[12] Ezerskaia A., Uzunbajakava N.E., Puppels G.J., de Sterke J., Caspers P.J., Urbach H.P., Varghese B. // Biomed. Opt. Express. 2018. V. 9. N 5. P. 2436.

[13] Березин К.В., Дворецкий К.Н., Чернавина М.Л., Нечаев В.В., Лихтер А.М., Шагаутдинова И.Т., Антонова Е.М., Тучин В.В. // Опт. и спектр. 2019. Т.127. В.2. С.329.

[14] Швачкина М.Е., Яковлев Д.Д., Лазарева Е.Н., Правдин А.Б., Яковлев Д.А. // Опт. и спектр. 2019. Т.127. В.2 C. 337.

[15] Gallwas J., Stanchi A., Ditsch N., Schwarz T., Dannecker C., Muller S., Stepp H., Mortensen U. // Lasers Med. Sci. 2015. V. 30. P. 517.

[16] Verdel N., Marin A., Milanic M., Majaron B. // Biomed. Opt. Express. 2019. V. 10. N 2. P. 944.

[17] Shurrab K., Kochaji N., Bachir W. // Pol. J. Med. Phys. Eng. 2019. V. 25. N 3. P. 141.

[18] Чурсинова Ю.В., Куликов Д.А., Рогаткин Д.А., Разницына И.А., Мосальская Д.В., Бобров М.А., Петрицкая Е.Н., Молочков А.В. // Biomedical Photonics. 2019. V. 8. N 1. P. 38.

[19] Dremin V.V., Dunaev A.V. // J. Opt. Technol. 2016. V. 83. N 1. P. 43.

[20] Zaytsev K.I., Dolganova I.N., Chernomyrdin N.V., Katyba G.M., Gavdush A.A., Cherkasova O.P., Komandin G.A., Shchedrina M.A., Khodan A.N., Ponomarev D.S., Reshetov I.V., Karasik V.E., Skorobogatiy M.A, Kurlov V.N., Tuchin V.V. // J. Opt. 2020. V. 22. N 1. P. 013001.

[21] Ramos-Soto D.I., Singh A.K., Saucedo-Casas E., CastroCamus E., Alfaro-Gomez M. // Appl. Opt. 2019. V. 58. N 24. P. 6581.

[22] Merle C., Laugel C., Chaminade P., Baillet-Guffroy A. // J. Liq. Chromatogr.Relat. Technol. 2010. V. 33. N 5. P. 629.

[23] Тучин В.В. Оптика биологических тканей. Методы рассеяния света в медицинской диагностике. 2-е издание. Физматлит, 2012. 811 c.; Tuchin V.V. Tissue Optics: Light Scattering Methods and Instruments for Medical Diagnostics. 3rd ed. Bellingham, WA: SPIE Press, 2015. 988 p.

[24] Bouma B.E., Tearney G.J. Handbook of optical coherence tomography. NY: Marcel Dekker Inc., 2002.

[25] Sdobnov A.Y., Darvin M.E., Genina E.A., Bashkatov A.N., Lademann J., Tuchin V.V. // Spectrochim. Acta A. 2018. V. 197. P. 216.

[26] Costantini I., Cicchi R., Silvestri L., Vanzi F., Pavone F.S. // Biomed. Opt. Express. 2019. V. 10. N 10. P. 5251.
[27] Inyushin M., Meshalkina D., Zueva L., Zayas-Santiago A. // Molecules. 2019. V. 24. N 13. P. E2388.

[28] Son T., Jung B. // Skin Res. Technol. 2015. V. 21. P. 327.

[29] Cu K., Bansal R., Mitragotri S., Fernandez R.D. // Ann. Biomed. Eng. 2019. P. 1573.

[30] Richardson D.S., Lichtman J.W. // Cell. 2015. V. 162. N 2. P. 246.

[31] Matryba P., Kaczmarek L., Gotqb J. // Las. Photonics Rev. 2019. V. 13. N 8. P. 1800292.

[32] Darvin M.E., Schleusener J., Parenz F., Seidel O., Krafft C., Popp J., Lademann J. // Analyst. 2018. V. 143. P. 4990.

[33] Khan M.H., Choi B., Chess S.M., Kelly K., McCullough J., Nelson J.S. // Lasers Surgery Med. 2004. V. 34. N 2. P. 83.

[34] Hirshburg J.M., Ravikumar K.M., Hwang W., Yeh A.T. // J. Biomed. Opt. 2010. V. 15. P. 055002.

[35] Yang N.J., Hinner M.J. // Methods Mol. Biol. 2015. V. 1266. P. 29.

[36] Ути, С.Р., Тучин В.В., Галкина Е.М. // Вестник дерматологии и венерологии. 2015. № 4. С. 60.

[37] Sdobnov A.Y., Tuchin V.V., Lademann J., Darvin M.E. // J. Phys. D. 2017. V. 50. N 28. P. 285401.

[38] Sdobnov A.Y., Darvin M.E., Schleusener J., Lademann J., Tuchin V.V. // J. Biophotonics. 2019. P. e201800283.

[39] Bohannon K.P., Holz R.W., Axelrod D. // Microsc. Microanal. 2017. V. 23. P. 978.

[40] Choe C., Choe S., Schleusener J., Lademann J., Darvin M.E. // J. Raman Spectrosc. 2019. V. 50. P. 945.

[41] Caspers P.J., Lucassen G.W., Carter E.A., Bruining H.A., Puppels G.J. // J. Invest. Dermatol. 2001. V. 116. N 3. P. 434.

[42] Choe C., Schleusener J., Lademann J., Darvin M.E. // J. Biophotonics. 2018. V. 11. N6. P. e201700355.

[43] Caspers P.J., Williams A.C., Carter E.A., Edwards H.G.M., Barry B.W., Bruining H.A., Puppels G.J. // Pharmaceutical Res. 2002. V. 19. N 10. P. 1577.

[44] Zimmerley M., McClure R.A., Choi B., Potma E.O. // Appl. Optics. 2009. V. 48. P. D79.

[45] Segur J.B., Oberstar H.E. // Ind. Eng. Chem. 1951. V. 43. N 9. P. 2117.

[46] Oliveira L., Tuchin V.V. The optical clearing method: A new tool for Clinical Practice and Biomedical Engineering. Basel: Springer Nature Switzerland AG, 2019.

[47] Wiechers J.W., Dederen J.C., Rawlings A.V. // Ed. by Rawlings A.V.R., Leyden J. Informa Health care. N.Y.: Taylor\&Francis Group, 2009. P. 309-321.

[48] Genin V.D., Tuchina D.K., Sadeq A.J., Genina E.A., Tuchin V.V., Bashkatov A.N. // J. Biomed. Photon. Eng. 2016. V. 2. N 1. P. 010303 . 